\title{
The Quantitative Analysis of Value for Money Evaluation: From the Perspective of Process Management
}

\author{
Liming Xia, Jiafeng Liu ${ }^{\text {a, }}{ }^{,}$, Peipei Liu \\ School of management, Tianjin University of Technology, Tianjin, China \\ aliu_jia_feng@163.com
}

Keywords: Value for money; Process management; Quantitative evaluation; PPP.

\begin{abstract}
At present, the imperfect of the development on PPP mode, the lack of mature operational experience on actual projects and the shortage of funds trigger local governments' urgent demands on the application of PPP model. Value for money, known as a scientific judgement basis for decision-makers, is commonly used to determine to choose PPP model or government's traditional model. To this end, this paper aims to improve the accuracy of the value for money evaluation and give a quantitative analysis from the perspective of process management. In particular, the definition of PPP value and PSC value is crucial. Results presented in this paper may provide some management insights on the development of China's PPP model.
\end{abstract}

\section{Introduction}

At present, the research on the concept of value for money in China is not deep, meanwhile the Ministry of Finance in our country has established "PPP value for money evaluation guidelines (trial)", in which the guidelines for evaluating value for money are not comprehensive, and only the concept of value for money evaluation, qualitative evaluation, quantitative evaluation, the contents of the report and information disclosure are introduced. However, the PPP value and the PSC value in the value for money evaluation are not perfect enough. At present, domestic scholars also conducted relevant research. For example, Huiqin Gao and Yunguo Liu [1] conducted a comparative analysis of the prevailing application status of the countries that implemented value for money internationally, providing the basis for establishing and perfecting the evaluation mechanism of PPP projects in our country. Hui Sun [2] introduced in the paper evaluation of value for money evaluation of ideas---the PPP value is compared with the PSC value, and at the same time, it introduces the related concepts, components and measurement process of public sector comparative value. Jiarong Li and Shouqing Wang [3] conducted a detailed analysis of the status quo and existing problems of the current PPP project decision-making system in China, and try to introduce value-for-money evaluation system to improve and perfect the pre-decision-making system of PPP projects in China, providing a scientific basis for the decision-making of PPP projects.

In foreign research, Grimsey.D and Lewis.M.K[4] conducted a comparative analysis of evaluation on value for money in 29 countries and regions, combined with the realities of Britain and Australia, they illustrated the basic components and assumptions of the comparative value of the public sector in the practice of comparative public sector value. Takim.R. \& Ismail.[5] conducted a comparative analysis of the prevailing value-for-money systems in the United Kingdom, Japan, Australia and Malaysia. After that, they improved and perfected Malaysian value-for-money system of that time, and proposed to the Malaysian government that it is essential to put forward relevant guidance documents such as the establishment of a public sector comparison value based on consideration of the drivers of value for money evaluation. Ismail.K.[5] conducted a comparative analysis of the public sector comparative valuations of Ireland, Australia, Hong Kong, South Africa and other countries, through which they obtained the key components and key elements that make up public-sector comparison.

In this paper, referring to the mature experience of foreign countries and the related theory of application process management, the author studies the value for money quantitative evaluation, and 
combined with the current situation of quantitative evaluation of value for money in China, the PPP value and PSC value are formulated completely.

\section{The Formulation of PPP Value and PSC Value}

\subsection{The Establishment of PPP Value and PSC Value Abroad}

Value for money means that the money is well spent. And commonly it means to "spend less money, do more things with good quality". Derived from Britain in the 1990s, this concept is defined by the British Audit Office as "optimizing the use of available resources for the desired outcome", including saving, efficiency and effect three aspects.

The quantitative evaluation of value for money is mainly by comparing the present value of the government spending over the life of the PPP project and that of the public sector. Through these we can determine a clear magnitude of value for money. The main steps of quantitative evaluation are as follows: (1) set a public sector comparison value; (2) make a shadow price; (3) calculate the difference between the public sector comparative value and the shadow price, if the shadow price is lower than the public sector comparative value, the value for money is positive, it shows that the PPP project passes the value for money quantitative evaluation; if not, it shows that the project did not pass the value for money quantitative evaluation.

The PPP value is the present value of the net cost of the government for the whole life cycle of the project, the PSC value refers to the public sector comparison value, however, in foreign countries, the term "shadow price" is used to represent the present value of the net cost of government in the project life cycle.

\subsubsection{The Formulation of Shadow Price}

The Federal Highway Administration of US department of Transportation defines shadow price as the estimated cost for governments to use the alternative financing and procurement model to build the same project and achieve the same output description. Among them, the alternative financing and procurement model mainly refer to the PPP model.

Shadow price includes government estimated PPP project contract price, relevant costs by government's adoption of PPP mode, also includes the cost of self-retention risk in most countries and regions. Specifically, if the corresponding public sector comparative value includes the cost of self-retention risk, shadow price should also include It., vice versa. Therefore, Britain, the United States, Canada, Hong Kong, etc. all adopt shadow price that cover the cost of self-retention risk. Shadow price in New Zealand do not include the cost of self-retention risk. Government estimated PPP project contract price is the amount estimated by government to make the PPP project financially viable. It mainly covers the costs incurred by social capital parties in the implementation of projects and the delivery of services and their reasonable returns. If social capital receives income from third parties and proceeds from other sources, those revenues and gains should be subtracted. If these revenues and benefits are enough to cover the costs and reasonable returns incurred by social capitalists, then there is no need for the government to pay the PPP contract price. The relevant expenses incurred by the government when adopting the PPP mode include purchasing expenses and other expenses incurred in facilitating the delivery of the project. In general, under the PPP mode, these related costs should only account for a small proportion of the total project cost, in practice, sometimes for simplification, these related costs are not considered in shadow price.

Based on the above payment characteristics of the PPP model in the country, the Canadian PPP Center proposes a more detailed shadow price structure, which includes the following six sections: (1) substantial completion payment / milestone payment; (2) capital repayments annuity; (3) non-capital repayment annuity; (4) transaction fee; (5) the purchase of compensation paid by the government directly to the unsuccessful social capital; (6) the cost of self-retention risk. 


\subsubsection{The Formulation of Public Sector Comparative Value}

Both HM Treasury and the Federal Highway Administration divided the public sector comparative value into four parts: (1) the basic cost, including total life-cycle costs such as construction investment, public procurement costs, supervisory costs, and operational maintenance costs of providing services for a predetermined number of years. Relatively speaking, the calculation of basic costs is easier, and there are more related information such as cost manuals, cost estimates; (2) financing costs, it refers to the cost of arranging financing for the project, usually related to bonds issued by traditional purchases in England; (3) risk-bearing costs, including the cost of self-retention risk and transferable risk-taking costs. The risk-bearing cost is an increase due to risk taking, including risk compensation. The cost of self-retention risk is the cost that the government is willing to pay for the risk of being retained in PPP mode, which includes the part that the government retains in both parties' shared risk. The transferable risk-taking cost is the cost that the government is willing to transfer to the social capital in PPP mode, and it includes the part of the shared risk to be borne by social capital; (4) the competitive neutral adjustment value, which can be used to eliminate the market distorting effect of the government's traditional procurement model.

Australian Infrastructure Centre has released a document "National PPP Guidelines (volume 4): Public Sector Comparator Guidance". And a document has been released by the state finance bureau in Victoria, Australia "Victoria Partner Guide: Practitioner's Guide", in which public sector comparison value is divided into four cores: (1) basic public sector comparative value, it is the cost incurred by the government in implementing projects and providing services and meeting the requirements of the PPP project output statement; (2) the competitive neutral adjustment value; (3) transferable risk-taking costs; (4) the cost of self-retention risk.

Therefore, it can be seen that basic public sector comparative value in Australia is the basic cost and the financing cost of the Anglo-American countries.

Finance national infrastructure center of New Zealand ministry has released "New Zealand PPP guide", in which it pointed out that the public sector comparative value consists of three parts: (1) the cost of project construction and operation; (2) the competitive neutral adjustment value; (3) the risks and any additional costs transferred to social capital in PPP mode. Among them, the cost of project construction and operation are substantially equivalent to basic public sector comparative value.

Canadian PPP center puts the public sector comparative value in special details, and it lists separately the income that is used to offset the cost to get the net cost value, it is divided into the following eight sections: (1) the construction cost, which usually includes three aspects: the basic cost of construction, the relevant cost of project management and licensing and insurance, the cost of obtaining approval from environmental authorities and regulatory authorities; (2) the cost of operation and maintenance and overhaul; (3) the reserve fee, which may also be called the unforeseeable fee; (4) rise fee of the cost; (5) government transaction costs; (6) the competitive neutral adjustment value; (7) income; (8) the cost of self-retention risk. The construction cost, the cost of operation and maintenance, government transaction cost basically corresponds to the content of basic public sector comparative value in other countries. The reserve fee and rise fee of the cost are basically corresponding to the cost of transferable risk in other countries.

\subsection{The Establishment of PPP Value and PSC Value in China}

"PPP value for money evaluation guidelines (trial)" has been published in China. It regulates that a quantitative assessment means that, with the assumption of adopting the PPP mode and the traditional output performance under the premise of the same investment way, through the whole life cycle of the PPP projects, by the comparison between net cost present value (PPP) of the government and the public sector values (PSC), it determines whether the PPP mode can reduce the total project life cycle cost. 


\subsubsection{The Establishment of PPP Value}

It is stipulated that the PPP value is equivalent to the present value of the equity investment, operation subsidy, risk self-retention and supporting investment of the total life cycle of PPP projects.

(1) The equity investment, its spending amount is determined based on the project capital and project company ownership structure. Its responsibility to pay should be assessed and estimated in accordance with the law such as land and other physical or intangible assets. Determine their relatively reasonable value according to these.

(2) The operating subsidy, its expenses are reasonably determined based on the cost of construction and operation and related profit levels, but it needs to be calculated separately according to different payment methods.

(3) Risk self-retention, its expenditures are estimated based on proportional method and probability method and methods of scenario analysis. If the project's PPP contract stipulates that the first beneficiary of an insurance claim is the government, its expenditure should be the net amount left after the risk compensation.

(4) Supporting investment, its expenditures are estimated based on the government and social capital side pays for the total cost of other supporting investment. Its responsibility to pay should be assessed and estimated in accordance with the law such as land and other physical or intangible assets. Determine their relatively reasonable value according to these.

\subsubsection{The Establishment of PSC Value}

The public sector comparison value is the sum of the present value of the life cycle. It includes the net cost of project construction and operation, the competitive neutral adjustment value and the total risk cost of the project.

(1) Construction net cost, including the cash invested in the design, construction, upgrading, renovation and overhaul of the reference projects as well as the value of physical and intangible assets such as fixed assets and land use rights, and it deducts the gain from transferring, leasing or disposing of the assets over the life cycle of the reference project.

(2) the net cost of operation and maintenance, mainly including the cost of raw materials, equipment and labor needed for the operation and maintenance of the reference project during the whole life cycle, as well as the management expenses, selling expenses and financial expenses during the operation period. And it deducts the user's paid income that can be obtained under the assumption that the reference project is the same as the PPP project's payment mechanism.

(3) The competitive neutral adjustment value, mainly using the traditional government investment than the use of PPP mode to implement the project less expenditure costs. It usually includes less cost of land, administrative examination and approval fees, related taxes and fees.

(4) The total risk cost of the project, which includes the risk-taking costs that can be transferred to social capital and the commitment costs of the government's retention-of-risk. The cost of government's retention-of-risk is equal to the full life-cycle risk-taking obligation of PPP. The two can be deducted equally between the PSC value and the PPP value.

\section{Analysis on the Composition of PPP Value and PSC Value Based on the Process Management}

\subsection{Comparative Analysis of the Composition of PPP Value and PSC Value}

It can be seen through the above analysis of domestic and foreign composition of PPP value and PSC value that, in the quantitative evaluation of value-for-money abroad, the PPP value is defined as the shadow price. It mainly includes the government estimated PPP project contract price, the PPP mode related costs by the adoption of government, in most countries and regions it also includes the cost of retained risk. However, China stipulates that the PPP value is equal to the present value of the financial expenditure responsibility such as equity investment, operation subsidy, risk commitment and supporting investment during the entire life cycle of the PPP project. But, PPP value refers to the 
present value of the net cost of government in the project life cycle. Through comparing the foreign countries with the domestic ones, we can see that there is a lack of a financing cost in the composition of value-for-money PPP in China, which can also be derived from the concept of project life cycle.

The composition of PSC in foreign countries is divided into four parts: (1) basic cost, including construction, operation and maintenance costs; (2) financing cost; (3) the cost of risk self-retention; (4) the competitive neutral adjustment value. However, China stipulates that the PSC value is composed of four items in "PPP value for money evaluation guidelines (trial)". It includes the net cost of construction and operation, the competitive neutral adjustment value and the project cost of total risk. By comparison, we can conclude that China lacks a financing cost compared with other countries.

\subsection{Construct the Composition of PPP Value and PSC Value Based on the Process Management}

The process management is a systematic approach. Its purpose is to continually improve the performance of the organization's business, and its focus is on building a standardized end-to-end business excellence process [6]. In other words, the process management is to link all aspects of the organization closely, but it must be ensured that the organization formed should be continuous, thorough and concise so that the organization can be more efficient and quicker in the future.

This research question applies the idea of process optimization in process management. Through the above comparative analysis, it is concluded that the composition of PPP value and PSC value in the quantitative evaluation lacks a financing cost. Financing costs are the costs that must be paid, because the fund users are in order to obtain the right to use funds. Financing costs include financing fees and capital charges. The structure of the PPP model and the government's traditional financing model are different, and the financing costs are also different. The PPP model is mainly undertaken by social capital, and the government needs to bear certain government subsidies. The traditional government model is that the government uses its own credit to bank loans. Under the PPP model and the government's traditional financing model, the corresponding financing costs are indefinite. Therefore, coupled with financing costs, the PPP values and PSC values can be more accurately compared. Process optimization in this study is to solve the problem of rearrange unreasonable links, it can make the conclusions drawn more convincing to improve the value of quantitative evaluation by optimizing the composition of PPP value and PSC value. Therefore, the cost of financing should be added to the composition of the PPP values and PSC values in the quantitative evaluation in China.

The PPP value should be the present value of each fiscal expenditure responsibility, including financing costs, equity investments, operating subsidies, risk self-retention and supporting inputs. The PSC value should include financing costs, the net cost of construction and operation maintenance, the competitive neutral adjustment value, the project cost of total risk.

\section{Conclusion}

This article starts with the composition of PPP value and PSC value in a quantitative evaluation of value for money, through the reference of domestic and foreign theoretical research on value for money evaluation, it has optimized the PPP value and PSC value in the quantitative evaluation of value for money in China based on the perspective of process management. At this stage, the composition of PPP value and PSC value in the quantitative evaluation does not include financing cost in China. After this article's research, added with the cost of financing, the PPP values and PSC values can be more accurately compared. Inevitably there are some shortcomings in the research of this article, and the view of value for money may not be enough profound, so we will continue to explore and innovate. 


\section{References}

[1]. Huiqin Gao, Yunguo Liu, Xia Qi, etc. Study on the VFM evaluation method based on the international practice of PPP model--take Britain, Germany and Singapore as an example [J]. Project management technology, 2011, 09(3): 18-21.

[2]. Hui Sun, Ying Zhou, Zhiqing Fan. The value theory and its application in the international community [J]. International economic cooperation, 2009(11): 70-74.

[3]. Jiarong Li, Shouqing Wang. The improvement and perfection of the decision-making system of PPP project in China. Project management technology, 2011, 09(5): 17-22

[4]. Grimsey D, Lewis M.K. Are public private partnerships value for money: evaluating alternative approaches and comparing academic and practitioner views. Accounting forum, 2005, 29(4): 345-378

[5]. Xiaoran Zhang. The value of urban rail transit PPP projects is quantitatively evaluated. Beijing: Beijing Jiaotong University, 2016

[6]. Wenxiang $\mathrm{Xu}$. On the development of business process management and the application of Chinese enterprises. Contemporary petrochemicals, 2012, 20(5): 42-46 